Host defense responses of CO441 and CL30 maize lines to Fusarium graminearum analyzed by comparative label-free quantitative proteomics

Lana M. Reid ${ }^{1}$ and Illimar Altosaar ${ }^{2}$

${ }^{1}$ Ottawa Research \& Development Centre, Agriculture and Agri-Food Canada, Ottawa, Ontario, K1A 0C6, Canada

${ }^{2}$ Department of Biochemistry, Microbiology and Immunology, University of Ottawa, Ottawa, Ontario, K1H 8M5, Canada

Corresponding author:

Illimar Altosaar

Department of Biochemistry, Microbiology and Immunology

University of Ottawa

Ottawa, Ontario, K1H 8M5, Canada

Phone: 1-613-562-5800 x 6371

E-mail: altosaar@uottawa.ca

Keywords: defense proteome, gel-free label-free LC-MS/MS, embryo, Fusarium, maize, resistance 


\begin{abstract}
Gibberella ear rot is a disease of maize associated with low yields and the production of harmful mycotoxins therein. The disease is caused by the infection of host Zea mays with fungal pathogen Fusarium graminearum. Resistant (CO441) and susceptible (CL30) inbred maize line kernels were inoculated with conidial suspensions of F. graminearum or water (controls). Ears of maize (cobs) from each line were harvested upon maturation and proteins were extracted from the embryo tissue of the kernels to study tissue-specific response of the host. Embryo proteins from both CO441 and CL30 lines were sequenced using mass spectrometry (LC-MS/MS) and quantified using Label Free Quantification (LFQ). Following filtering, 509 proteins were identified. These proteins were grouped into nine functional categories: Fusarium-derived, late embryogenesis abundant, oil-body, metabolism, stress, cellular, protein storage, metabolism, and defense. Defense proteins were up-regulated in response to infection in both CO441 and CL30 lines. Furthermore, F. graminearum derived proteins were only found in CL30 infected kernels suggesting that resistance may be attributed in part to the inability of Fusarium to establish itself in the embryo. To our knowledge this is the first successful application of LFQ mass spectrometry to the study of host-pathogen response to F. graminearum.
\end{abstract}

\title{
Biological significance
}

Fungal pathogen Fusarium graminearum is responsible for billion dollar losses in crops and contamination of global grains with harmful mycotoxins. By studying host-pathogen interactions of Fusarium and maize on a proteomic level with resistant and susceptible genotypes, the biological interactions occurring during infection of the maturing seed were characterized. Mature kernels of the $F$. graminearum susceptible maize line CL30 and resistant CO441 line were dissected to permit a proteomic survey of the new sporophytic generation, the embryo. Detailed knowledge of this Host-pathogen interactome will assist development of new cereal lines resistant to the rot diseases caused by Fusarium graminearum.

\section{Highlights}

Susceptible (CL30) and Resistant (CO441) lines were injected with water mock or F. graminearum LC-MS/MS of maize embryo protein extracts followed by Label Free Quantification (LFQ) permitted identification, quantification and comparison of proteomes between maize genotypes and treatments Fusarium-derived proteins were abundant only in the susceptible infected embryo Defense proteomes were up-regulated in both lines following infection nsLTP and Protease Inhibitor were significantly over-expressed in the Susceptible line after infection; chitinase and WIP1 were significantly over-expressed in the Resistant line after infection 


\section{Introduction}

Fusarium graminearum (also referred to as Gibberella zeae in its sexual form) is an ascomycetic fungus and the etiological agent of crop diseases including head blight or scab disease on wheat and ear or stalk rot of maize [1]. Estimates of damage caused by F. graminearum in wheat alone exceeded $\$ 2.7$ billion between the years 1998 and 2000, making characterization of these plant-pathogen interactions a pressing concern [2]. Furthermore, chronic exposure to F. graminearum in humans has been linked to neurological and immunosuppressive disorders such as toxic aleukia and Akakabi toxicosis [2,3].

The genome of the PH-1 strain of F. graminearum was sequenced in 2007, enabling the identification of other putative virulence determinants [4]. Among the determinants expressed by Fusarium and other filamentous fungi are degradative enzymes such as pectinases, amylases, and proteases, which are important for functions including nutrient acquisition and establishment in the host [5-7].

In the early stages of infection, Fusarium appears to colonize plant cells primarily by secreting cell-wall degrading enzymes [8]. Fusarium exhibits hemi-biotrophic behavior. Only after replication and intracellular growth of F. graminearum, cell and tissue necrosis are observed. Necrosis is thought to correlate with the release of the Fusarium, permitting additional infectious cycles to take place on remaining living tissue [9].

Once in the host, Fusarium causes biochemical changes. A major orchestrator of these biochemical changes is the trichothecene deoxynivalenol (DON). The Tri5 gene cluster in the pathogen encodes for trichothecene synthase and disruption of this gene cluster has been linked with lower disease severity [10]. Amine inducers, low pH, reactive oxygen species (ROS) and certain phenolic acids have been recognized as inducers of DON biosynthesis [11-14]. Studies have implicated DON as a major virulence factor, however, the mechanism by which it confers virulence is unknown [15].

Infection of maize can induce various host defense mechanisms including the production of nitric oxide, ROS, phytoalexins and pathogenesis-related (PR) proteins [16,17]. Additionally, phenolic acid abundance in the cell has been linked with increased resistance to fungal disease [14]. Phenolics confer an antifungal effect and are involved in the fortification of the plant cell walls through esterification [18]. In maize and wheat, the cell walls contain an abundance of phenolic acids such as ferulic and p-coumaric acids. Following infection, cell wall-bound phenolic compounds increase. These hydroxycinnamic acids in 
particular have been linked with resistance to Fusarium in maize kernels [19]. The molecule p-hydroxybenzoic acid has been found to reduce TRI5 expression and DON biosynthesis whereas the production of ferulic acid has been linked with activation of DON biosynthesis [14]. Therefore, resistance may stem from differences in phenolic acid production among plants.

PR proteins are defensive proteins expressed by the plant upon challenge by a pathogen and are classified into 17 families based on their role and molecular characteristics [20]. A recent study shows that a large majority of up-regulated proteins in maize following F. graminearum infection are PR proteins such as chitinase and thaumatin-like protein [1]. In wheat, expression of $\beta$-1, 3-glucanases (PR-2) and chitinases (PR-3) was found in greater abundance in the resistant line Arina when compared to the susceptible line, Agent [21]. These proteins confer protection by catalyzing the hydrolysis of fungal cell wall constituents, chitin and $\beta$-1, 3-glucan [22]. Further studies on the PR protein response may help identify other key defenders in the plant-Fusarium interactome.

The objective of the present study was to determine differences in defense protein expression between maize genotypes and in their proteomes following F. graminearum inoculation. It was hypothesized that defense proteins of maize embryos infected with F. graminearum are differentially expressed depending on their genotypes. To test this hypothesis, analysis of the maize embryo under the different experimental treatments was assessed using an aqueous protein extraction method and gel free LC-MS/MS followed by label free quantification (LFQ) proteomics.

\section{Materials and Methods}

\subsection{Maize harvesting and kernel sampling}

Experimental procedures were performed as described in [23]. F. graminearum resistant maize inbred line (CO441) and susceptible line (CL30) were planted on the Central Experimental Farm in Ottawa, ON, Canada. Maize kernels were inoculated with either water (control) or with F. graminearum conidial suspensions. Kernels were injected using a four-pin automatic kernel inoculator, 10-15 days post-silk emergence [24]. F. graminearum strain DAOM180378 was used and conidial suspensions were prepared at $5 \times 10^{5}$ conidia $/ \mathrm{mL}$. Ears of both fungal and water treated maize were harvested at maturity and stored in brown paper seed bags at $-20{ }^{\circ} \mathrm{C}$ until further analysis. 


\subsection{Protein extraction from embryo}

Embryo protein extracts were obtained from each treatment ( 1 sample $=16$ kernels $)$. Kernels were washed with a $10 \%$ sodium hypochlorite solution for 5 min followed by five washes in $\mathrm{ddH}_{2} \mathrm{O}$. Washed kernels were placed on sterile Whatman paper and left to dry overnight in the laminar flow hood. Dried kernels were incubated $15 \mathrm{~h}$ in $0.3 \%(\mathrm{w} / \mathrm{v})$ sodium metabisulphite and $85 \%(\mathrm{v} / \mathrm{v})$ lactic acid at $37{ }^{\circ} \mathrm{C}$. Embryo tissues were dissected using a surgical scalpel. Tissue was homogenized with $20 \mathrm{~mL}$ of aqueous protein extraction buffer (10mM Tris- $\mathrm{HCl} \mathrm{pH}$ 7.8, $0.5 \mathrm{mM}$ EDTA, $10 \mathrm{mM} \mathrm{KCl,} \mathrm{1mM} \mathrm{PMSF} \mathrm{(protease}$ inhibitor) adjusted to $\mathrm{pH} 7.8$ ) at $4{ }^{\circ} \mathrm{C}$. Homogenates were centrifuged at $14,000 \mathrm{~g}$ for $10 \mathrm{~min}$ at $4{ }^{\circ} \mathrm{C}$. $70 \%$ of the supernatant was removed and placed into fresh tubes. Pellets were re-suspended in the remaining supernatant and centrifuged a second time. Supernatants from each sample were pooled together and protein was precipitated with pre-chilled acetone ( 4 volumes) at $-20{ }^{\circ} \mathrm{C}$ for $1 \mathrm{~h}$ and centrifuged at $14,000 \mathrm{~g}$ for $20 \mathrm{~min}$ at $4{ }^{\circ} \mathrm{C}$. The subsequent protein pellets were washed twice with acetone and left to air dry in the laminar flow hood. Protein extracts were stored at $-80{ }^{\circ} \mathrm{C}$.

\subsection{Quantification of protein extracts}

A Bradford assay was used to determine the concentration of protein in each sample [25]. SDS-PAGE using a 15\% acrylamide separating gel using Tris-glycine buffer was performed to confirm the presence of protein in each sample [26]. Ten $\mu \mathrm{g}$ of each sample was used for mass spectrometric protein sequencing and quantification by the Ottawa Institute of Systems Biology (OISB).

\subsection{Mass Spectrometry (LC-MS/MS)}

A detailed description of methods for LC-MS/MS is provided in the supplemental files (Supplemental 2). Protein extracts were dissolved in $8 \mathrm{M}$ urea, reduced and alkylated. Samples were digested with trypsin and the resulting peptides were analyzed by high-performance liquid chromatography/electrospray ionization tandem mass spectrometry (HPLC-ESI-MS/MS) [27]. The acquired MS/MS spectra were searched against Zea mays (Uniprot taxon: 4577 and 76912) and Gibberella zeae PH-1 (Uniprot taxon: 229533) Uniprot protein sequence databases (version 3.85) using MaxQuant (Martinsried, Germany) with the label free quantification (LFQ) option. The false discovery rates (FDR) for both the protein and peptide levels were set to $\leq 1 \%$. Quantification was performed using normalized LFQ intensity [28]. 


\subsection{Data Analysis}

Data from each set of biological duplicates were combined and an average of their LFQ intensities was calculated. Maize protein hits from each sample ( 4 samples, each with $n=2$ ) were manually assigned to a functional group based on their role in the cell, and groups were as follows: late embryogenesis abundant (LEA), protein storage, cellular, metabolism, defense, stress response, oil-body, and uncharacterized. Statistically significant changes in defense protein expression were reported when a given protein compared between two samples passed a Significance B test (at $P<0.05$ ) with the MaxQuant/Perseus software (version 1.3.0.4). A full description of Significance B testing is given by Cox and Mann [28]. To better describe uncharacterized proteins, their homologs were matched using a basic local alignment search tool (BLAST) search and the NCBI protein database [29].

\section{Results}

The experimental model involved injection of maize kernels with Fusarium or with water (control). Visual observation of the susceptible line (CL30) indicated aggressive Fusarium infestation and rot (Figure 1). Neither the resistant infected and resistant water treated maize displayed any visible signs of disease.

\subsection{Proteins identified}

Cumulatively, 951 proteins were identified following mass spectrometry. This list of protein hits was filtered for reverse hits, contaminants, posterior error probability $(P E P)<0.05$ and proteins with fewer than two peptide counts. Following filtering, the list consisted of 509 proteins in total (Supplemental 1).

\subsection{Organismal and functional grouping of proteins}

Maize protein hits were manually classified into eight groups based on their biological function in the cell: late embryogenesis abundant (LEA), oil-body, metabolism, stress, cellular, protein storage, metabolism, and defense (Figure 2).

LEA protein abundance was $44.2 \%, 31.3 \%, 9.64 \%$ and $27.3 \%$ of the total maize protein in resistant watertreated $\left(\mathrm{R}_{\mathrm{W}}\right)$, resistant Fusarium-treated $\left(\mathrm{R}_{\mathrm{F}}\right)$, susceptible water-treated $\left(\mathrm{S}_{\mathrm{W}}\right)$ and susceptible Fusarium- 
treated $\left(\mathrm{S}_{\mathrm{F}}\right)$, respectively. Following infection, the absolute value of LEA protein abundance (represented by LFQ intensity) decreased by a factor of 0.560 in the resistant line and increased by a factor of 4.06 in the susceptible line.

Storage protein abundance was $11.1 \%, 10.3 \%, 10.0 \%$ and $2.88 \%$ of the total maize protein in $\mathrm{R}_{\mathrm{W}}, \mathrm{R}_{\mathrm{F}}, \mathrm{S}_{\mathrm{W}}$ and $\mathrm{S}_{\mathrm{F}}$, respectively. Following infection, the absolute value of LEA protein abundance (represented by LFQ intensity) decreased by a factor of 0.733 in the resistant line and by a factor of 0.412 in the susceptible line.

Cellular protein abundance was $4.71 \%, 4.96 \%, 7.99 \%$ and $2.30 \%$ of the total maize protein in $\mathrm{R}_{\mathrm{W}}, \mathrm{R}_{\mathrm{F}}, \mathrm{S}_{\mathrm{W}}$ and $\mathrm{S}_{\mathrm{F}}$, respectively. Following infection, the absolute value of LEA protein abundance (represented by LFQ intensity) decreased by a factor of 0.833 in the resistant line and by a factor of 0.413 in the susceptible line.

Metabolism protein abundance was $3.21 \%, 4.28 \%, 11.7 \%$ and $1.78 \%$ of the total maize protein in $\mathrm{R}_{\mathrm{W}}, \mathrm{R}_{\mathrm{F}}$, $\mathrm{S}_{\mathrm{W}}$ and $\mathrm{S}_{\mathrm{F}}$, respectively. Following infection, the absolute value of LEA protein abundance (represented by LFQ intensity) increased by a factor of 1.05 in the resistant line and decreased by a factor of 0.219 in the susceptible line.

Stress response protein abundance was $1.89 \%, 1.27 \%, 1.20 \%$ and $0.513 \%$ of the total maize protein in $\mathrm{R}_{\mathrm{W}}, \mathrm{R}_{\mathrm{F}}, \mathrm{S}_{\mathrm{W}}$ and $\mathrm{S}_{\mathrm{F}}$, respectively. Following infection, the absolute value of LEA protein abundance (represented by LFQ intensity) decreased by a factor of 0.530 in the resistant line and by a factor of 0.613 in the susceptible extracts.

Oil-body protein abundance was $5.93 \%, 7.11 \%, 5.78 \%$ and $0.854 \%$ of the total maize protein in $R_{W}, R_{F}$, $\mathrm{S}_{\mathrm{W}}$ and $\mathrm{S}_{\mathrm{F}}$, respectively. Following infection, the absolute value of LEA protein abundance (represented by LFQ intensity) decreased by a factor of 0.947 in the resistant line and by a factor of 0.212 in the susceptible line.

Uncharacterized protein abundance was $15.0 \%, 18.8 \%, 20.3 \%$ and $21.2 \%$ of the total maize protein in $\mathrm{R}_{\mathrm{W}}, \mathrm{R}_{\mathrm{F}}, \mathrm{S}_{\mathrm{W}}$ and $\mathrm{S}_{\mathrm{F}}$, respectively. Following infection, the absolute value of LEA protein abundance (represented by LFQ intensity) decreased by a factor of 0.995 in the resistant line and increased by a factor of 1.50 in the susceptible line. 
Defense protein abundance was $14.02 \%, 21.2 \%, 33.3 \%$ and $43.2 \%$ of the total maize protein in $\mathrm{R}_{\mathrm{W}}, \mathrm{R}_{\mathrm{F}}$, $\mathrm{S}_{\mathrm{W}}$ and $\mathrm{S}_{\mathrm{F}}$, respectively. Following infection, the absolute value of LEA protein abundance (represented by LFQ intensity) increased by a factor of 1.24 in the resistant line and by a factor of 1.86 in the susceptible extracts.

Proteins were also classified based on the organism from which they were derived (maize or F. graminearum) (Figure 2). Maize-derived proteins comprised the majority of proteins in the samples with Fusarium proteins contributing $0.0111 \%, 0.0124 \%, 0.0166 \%$ and $4.38 \%$ of the total proteins in $\mathrm{R}_{\mathrm{W}}$, $\mathrm{R}_{\mathrm{F}}, \mathrm{S}_{\mathrm{W}}$ and $\mathrm{S}_{\mathrm{F}}$, respectively. Fusarium abundance in $\mathrm{R}_{\mathrm{F}}$ differed by a factor of 0.90 when compared to the non-infected control. $\mathrm{S}_{\mathrm{F}}$ contained the most Fusarium-derived proteins, 378 times greater in comparison to the $\mathrm{S}_{\mathrm{W}}$ baseline. Protein quantities used in this initial functional and organismal classification were not statistically tested for significance.

A total of 17 Fusarium-derived proteins were identified, all uncharacterized. A BLAST search of the amino acid sequences was used to identify proteins in other organisms that shared similar homology. The homologs with greatest similarity (sharing $>50 \%$ identity) were as follows: UniProt: I1S0I4 shared 100\% identity with Snodprot from Fusarium graminearum (Uniprot: Q5PSV7). UniProt: I1RLE0 shared 100\% identity with Alkaline foam protein B found in Fusarium culmorum (Uniprot: A1XCJ0). UniProt: I1RQB6 shared 97.0\% identity with Glyceraldehyde-3-phosphate dehydrogenase found in Fusarium oxysporum (Uniprot: F9FK90). UniProt: I1RL08 shared 84.0\% identity with Small secreted protein from Fusarium solani subsp. pisi (Uniprot: C7Z066). UniProt: I1RC55 shared 78.0\% identity with Heat shock protein 30 found in Cylindrocarpon tonkinense (Uniprot: C3VMP2). UniProt: I1S341 shared 78\% identity with Eliciting plant response-like protein (Ep11) from Trichoderma asperellum (Uniprot: E3UTB4). UniProt: I1RSM6 shared 69.0\% identity with Glucose repressible protein (Grg1) found in Cordyceps militaris strain CM01 (Uniprot: G3JKJ7) (Supplemental 1).

\subsection{Significant changes in protein expression}

Using Label Free Quantification (LFQ) intensities, a Significance B test $(P<0.05)$ was performed to compare expression changes between samples with either identical genotypes (resistant/susceptible) or identical treatments (water/Fusarium injected). A total of 68 proteins was determined to have changed significantly in at least one two-sample comparison (Supplemental 1). Of this total, 13 defense proteins were deemed to change significantly. Defense proteins that were up-regulated following infection in the 
resistant line $\left(\mathrm{R}_{\mathrm{F}} / \mathrm{R}_{\mathrm{W}}\right)$ were chitinase (Uniprot: B8QUX1 and Q6KBR1), basic endochitinase A (Uniprot: B6TR38), $\beta$-1, 3-glucanase (UniProt: E1AFV5), catalase (UniProt: B6UHU1) and Bowman-Birk type wound-induced proteinase inhibitor WIP1 (UniProt: B4FYK1). Proteins down-regulated between $R_{F} / R_{W}$ were non-specific lipid transfer protein (UniProt: B6T1X4, B6SP11 and B6T2T4), glutathione peroxidase (Uniprot: B6TR92) and Lipoxygenase (Uniprot: Q8W0V2) (See Table 1 for values).

In the $\mathrm{S}_{\mathrm{F}} / \mathrm{S}_{\mathrm{W}}$ and $\mathrm{R}_{\mathrm{W}} / \mathrm{S}_{\mathrm{W}}$ comparisons, glutathione peroxidase (Uniprot: B6TR92) was up-regulated. Comparing the infected resistant to the infected susceptible genotype $\left(\mathrm{R}_{\mathrm{F}} / \mathrm{S}_{\mathrm{F}}\right)$, there was an up-regulation of $\beta$-1, 3-glucanase (UniProt: E1AFV5) and non-specific lipid transfer protein (Uniprot: B6SGP7). Down-regulated proteins included protease inhibitor (Uniprot: Q2XWZ0) and non-specific lipid protein (Uniprot: B6SP11). Furthermore, the protein score represented a $\log _{2}$ transformation of the posterior error probability (PEP) and was calculated by MaxQuant software. High scores indicate greater confidence of a protein being identified correctly. The highest scores were attributed to chitinases (3000 and 2860) and the lowest score was attributed to catalase (90.9) (Table 1).

\section{Discussion}

\subsection{Susceptibility - Fusarium establishes itself within the host-embryo}

Label Free Quantification (LFQ) permitted relative quantification of protein among all samples (Figure 2). By searching against the recently sequenced genomes of Zea mays and Fusarium graminearum, peptide hits were used to determine their corresponding protein IDs [4,30]. These Protein IDs were manually assigned to a functional group depending on their biological function in the cell. Grouping allowed for a determination of the respective effects of maize genotypes and treatment on defense protein expression. Without F. graminearum infection, defense protein expression changed by 0.528 fold in the resistant when compared to the susceptible proteome $\left(\mathrm{R}_{\mathrm{W}} / \mathrm{S}_{\mathrm{W}}\right)$. Following infection with F. graminearum this value changed to $0.353\left(\mathrm{R}_{\mathrm{F}} / \mathrm{S}_{\mathrm{F}}\right)$. Furthermore, defense protein expression increased by a factor of 1.24 in the resistant line $\left(\mathrm{R}_{\mathrm{F}} / \mathrm{R}_{\mathrm{W}}\right)$ and by a factor of 1.86 in the susceptible extracts $\left(\mathrm{S}_{\mathrm{F}} / \mathrm{S}_{\mathrm{W}}\right)$. This suggested that the susceptible line expressed a greater abundance of defense proteins (compared to the resistant line) regardless of treatment and that both the resistant and susceptible lines up-regulated their defense response following the fungal attack. The resistant genotype may have expressed proteins that are more effective for preventing the establishment of F. graminearum in the embryo. As such, more drastic 
changes in expression levels of the defense proteome were not required. To our knowledge, this theory has yet to be explored and consequently, further studies are needed for validation.

Proteins were also classified according to whether they were maize-derived or Fusarium-derived. The majority of the proteins identified $(>90 \%)$ were maize-derived. A low quantity of Fusarium proteins were found in samples extracted from both $\mathrm{R}_{\mathrm{W}}$ and $\mathrm{S}_{\mathrm{W}}$. These were used as baseline values (these samples serve as negative controls). In the $\mathrm{R}_{\mathrm{F}}$ protein extracts, there was very little evidence for the presence of Fusarium peptides remaining through the field growing season past harvest and storage time (a 0.90 fold difference in response to infection). This implies that the fungus was unable to establish itself in the embryo. In the $\mathrm{S}_{\mathrm{F}}$ sample, however, there was a 378 fold increase in response to infection, implying that the fungus is able to establish itself in the embryo. From these data, we propose that resistance to Fusarium is due in part to the inability of the fungus to establish itself in the embryo. The expression of specific proteins may be the link between what constitutes an efficient defense response (resistant genotype) and a non-sufficient response (susceptible genotype). This finding also suggests a new research frontier, one in which proteomic sampling throughout the growing season might be able to track fungal proteins of varying persistence in the host endosperm milieu. Finally, the lower abundance of F. graminearum protein hits indicates that these proteins are not recalcitrant enough to remain detectable after six weeks of grain development and maturation.

\subsection{Defense and Pathogenesis-related proteins}

To achieve a more stringent picture of expression changes potentially occurring between treatments and genotypes, a Significance B test was performed. Thus, the total list of 509 proteins was reduced to 68 proteins. Using this reduced list to compare the resistant to the susceptible genotype, there was a greater number of proteins whose expression changed significantly in the resistant genotype following infection. Despite this, the overall abundance of defense proteins was greatest in the susceptible genotype following infection.

Infection of plants induces various defense mechanisms including the production of reactive oxygen species (ROS) by class III peroxidases. The generation of these ROS generates toxic environments for the pathogen [31]. Overabundances of these ROS, however, can be harmful to the host plant. To reduce this oxidative stress, glutathione peroxidases (GPxs) are expressed. GPxs prevent oxidative damage to the host membrane by lipid peroxidation repair. In transgenic tobacco, expression of Chlamydomonas glutathione 
peroxidase was found to confer greater tolerance to oxidative stress [32]. Repair from this oxidative stress is achieved through the reduction of various organic and hydro-peroxides to their respective hydroxyl compounds [32]. In the present experiment, the glutathione peroxidase level was reduced by two-fold in the resistant line following treatment with F. graminearum $\left(\mathrm{R}_{\mathrm{F}} / \mathrm{R}_{\mathrm{W}}\right)($ Table 1$)$. These data suggest oxidative stress in the resistant genotype did not reach levels that would require protection of the host membrane and consequently, the expression of GPx was down-regulated.

Non-specific lipid transfer proteins (nsLTPs) are small cysteine-rich proteins involved in the shuttling of lipids and hydrophobic molecules between membranes [33]. The nsLTPs are implicated with plant defense following biotic and abiotic stresses and are able to form protective extracellular waxy and cutin polymeric layers through the deposition of hydrophobic monomers $[33,34]$. Furthermore, nsLTPs are able to confer antimicrobial properties in vivo, although this is not conserved across all nsLTPs [34]. The nsLTPs from maize leaf protein extracts were found to have an inhibitory effect on Fusarium solani growth [35]. In the current study, the nsLTPs increased most following infection of the susceptible genotype $\left(\mathrm{S}_{\mathrm{F}} / \mathrm{S}_{\mathrm{W}}\right)$. In contrast, the resistant genotype was associated with a decrease in nsLTP levels following infection $\left(\mathrm{R}_{\mathrm{F}} / \mathrm{R}_{\mathrm{W}}\right)$. This suggests that in this study, nsLTPs have a greater role in pathogen defense response in the susceptible genotype compared to the resistant. The effectiveness of nsLTPs depends both on the pathogen and the specific nsLTP expressed (there are many with different function and activity). In a previous study, F. graminearum was among the fungi least inhibited by wheat nsLTP [33]. There, only three out of eight nsLTPs were shown to provide at least a moderate level of antifungal activity. In the context of the current report, observations from the Sun study suggest that susceptibility is not a result of an absent defense response, but rather the result of an ineffective one. Furthermore it suggests that the resistant genotype is not as dependent on these proteins as a means of defense, relying instead on other more effective PR-proteins.

Another defense-related protein that we observed to change significantly was $\beta$-1, 3-glucanase. The enzyme $\beta$-1, 3-glucanase catalyzes the hydrolysis of fungal cell walls by cleaving $\beta$-1, 3-glucan [36]. Transgenic wheat lines expressing $\beta$-1, 3-glucanase have been linked with increased resistance to Fusarium infection [37]. In our maize embryos, there was no significant change in abundance of $\beta$-1, 3-glucanase between $S_{F} / S_{W}$, however, there was a 12.4 fold increase between $R_{F} / R_{W}$. These data suggest that expression of $\beta$-1, 3-glucanase is induced by Fusarium infection in the resistant genotype but is unaffected in the susceptible genotype. 
Chitinases are major PR proteins involved in the exo or endo $\beta$-1, 4-glycosidic cleavage of $\mathrm{N}$-acetylglucosamine (chitin). Fungal cell walls are comprised of chitin, therefore chitinases confer antifungal properties by disassembling the structural network of these cell walls [38,39]. When maize was challenged with F. graminearum we found that chitinase expression was up-regulated in the infected resistant line compared to the water treated resistant line by 8.11 fold $\left(\mathrm{R}_{\mathrm{F}} / \mathrm{R}_{\mathrm{W}}\right)$. Comparing the two genotypes, chitinase (UniProt Q6JBR1) was expressed 30.68 fold greater between $\mathrm{R}_{\mathrm{F}} / \mathrm{S}_{\mathrm{F}}$, implicating it in the resistance trait. These data are consistent with another study with CO441, but one using gel spot excision. Chitinase expression was greater in the CO441 resistant genotypes in comparison to susceptible and increased further upon infection with Fusarium [1].

Wound-induced protease inhibitor 1 (WIP1) increased significantly following F. graminearum infection in the resistant line $\left(\mathrm{R}_{\mathrm{F}} / \mathrm{R}_{\mathrm{W}}=9.32\right)$. WIP1 is environmentally regulated in plant tissues and induction of WIP1 is confined to the site of wounding [40]. Mohammadi et al, 2011 found increased WIP1 in the resistant CO441 line (both infected and non-infected samples) compared to the susceptible B73 suggesting that resistance may be due to these wound-inducible protease inhibitors [1]. In the present study, we observed an increase in expression of WIP1 in response to Fusarium challenge $\left(\mathrm{R}_{\mathrm{F}} / \mathrm{R}_{\mathrm{W}}\right)$, however, there were no significant changes between the susceptible duplicates as a result of infection $\left(\mathrm{S}_{\mathrm{F}} / \mathrm{S}_{\mathrm{W}}\right)$, reinforcing the notion that expression of this specific protease inhibitor is governed by factors other than wounding, in this case genotypic differences. These data suggest that resistance may be due to an up-regulation of WIP1 as it is important in defense against pathogen in the early stages of colonization.

Fungi secrete a variety of proteases upon infection that facilitate colonization [7]. Host plants, including maize, are known to express protease inhibitors upon fungal challenge [40,41]. In maize, protease inhibitor abundance was found to increase in resistant (CO441) and susceptible (B73) genotypes following F. graminearum infection and expression was overall greater in the resistant genotype compared to the susceptible, regardless of treatment (see Table 3 in [1]). The present experiment, however, produced confounding observations. Protease inhibitors were less abundant in the resistant compared to the susceptible line following infection $\left(\mathrm{R}_{\mathrm{F}} / \mathrm{S}_{\mathrm{F}}=0.00367\right)$ (Table 1). A possible explanation for this may be that the resistant line halts the infection in the early stages and as such, no additional action by the host is required to defend against $F$. graminearum. In contrast, the susceptible plant may not be able to prevent Fusarium from colonizing and must therefore attempt to combat fungal protease activity in real-time during the course of the disease, resulting in the up-regulation of protease inhibitors. As WIP1 was observed to be induced only in the resistant line, the susceptible line relies instead on general protease inhibitors for defense, likely at a later time than these wound-induced protease inhibitors. 


\subsection{Model of resistance - chitinase is strategic during early stages of infection}

The data suggest that chitinase plays a major role in resistance: Fusarium is unable to establish itself in the embryo of resistant lines as chitinase destroys the fungus in early stages of infection. The chitinase response from the susceptible host is absent or inadequate due to a possible delay in salicylic acid response. As a consequence of this delayed response, Fusarium may be able to overpower host-defenses and infect.

The exact role of protease activity by F. graminearum is complex; however, it may prove important to the severity and rate of disease progression. The susceptible host genotype appears to depend primarily on nsLTP up-regulation to defend against F. graminearum (Table 1); however, the proteins are not sufficient or effective in combating the fungus. Consequently, the susceptible maize embryo may attempt to counteract the degradative nature of such Fusarium-derived proteases by expressing protease inhibitors. According to this proposed model (Figure 3) the resistant phenotype prevents early entry of Fusarium through increased expression of WIP1 (Table 1) and as a result, fungal establishment in the embryo is rendered unfavorable.

Introduction of compounds such as salicylic acid and ethylene are known to induce increases in chitinase production and disease resistance in plants [42-44]. Salicylic acid is an essential signaling molecule for plant defense against phytopathogens and other biotic stresses [44]. Moreover, studies of Fusarium infection in wheat have shown that susceptibility likely arises due to the delayed activation of the salicylic defense pathway [45]. If this mechanism occurs in maize as well, it is possible that Fusarium colonizes the embryo of the susceptible plant due to downstream effects of this delayed salicylic acid pathway. This may result in a delayed chitinase response providing the fungus with an opportunity to colonize and penetrate more deeply into the starch rich tissue reserves of the developing seed.

In summary, given these considerations on maize response to Fusarium infection as measured by LFQ proteomics, LFQ has provided novel insights into the cross-talk between host and pathogen. However, a caveat to such analyses and inferences regarding plant-pathogen interactions on a proteomic level, as described in the literature to date, is the difficulty of reproducibility. Use of different inoculation methods, hosts, pathogens and protein extraction procedures not to speak of mass spectrometer differences, results in inconsistencies between experimental models and their resultant data sets. This may explain why so little overlap is found between studies, as recently underscored by Finnie et al, 2013 [46]. Using the same 
material and experimental techniques on the pericarp and endosperm tissue will allow for the elucidation of biochemical processes occurring from fungal attack, retaining consistency in experimental methods.

As the endosperm and pericarp are apoptotic tissues of the grain it is expected that mass spectrometric analysis will reveal relatively fewer protein hits and lower amounts of these proteins. The current results therefore predict that a greater representation of cell wall degrading enzymes and amylases will be found in the pericarp and endosperm tissues respectively, as the fungus attempts to modify its protein expression to optimize nutrient acquisition and overcome the protective outer casing of the maturing maize kernel.

\section{Conclusion}

Cumulatively, 509 proteins were identified in the eight maize embryo samples and functionally classified in accordance to their biological function. The defense group in resistant and susceptible maize increased following infection by F. graminearum. Interestingly, the stress response and uncharacterized groups showed least change following fungal challenge in the embryo. Furthermore, these data indicated F. graminearum is able to establish itself in the susceptible embryo but not in the resistant. When testing for significantly expressed proteins between samples, up-regulation of chitinases and non-specific lipid transfer proteins was observed following infection in the resistant and susceptible genotypes, respectively. Therefore, it was proposed that the diseased phenotype is directly linked to an inadequate defense response. A successful defense response is dependent on the ability of disarming F. graminearum before the fungus establishes itself in the host.

\section{Acknowledgements}

Project was funded by Natural Sciences and Engineering Research Council of Canada (NSERC). We would also like to thank Dr. Zhibin Ning (OISB), Dr. Adam Koziol (CFIA), and Jason El Bilali for their technical assistance in this project; and we are very grateful to Dr. Kin Chan for stimulating guidance and helpful discussions. 


\section{Figure Captions}

\section{Figure 1: Resistant and susceptible maize injected with water or F. graminearum.}

Resistant (CO441) and susceptible (CL30) maize kernels were inoculated 10-15 days after flowering and ears were harvested at maturity at the Central Experimental Farm, Ottawa.

\section{Figure 2: Defense protein expression responded to $F$. graminearum inoculation.}

Top: Functional grouping of maize proteins identified in the embryo. Protein IDs were manually assigned to a group depending on their biological function. Groups were as follows: Uncharacterized, Oil Body, Stress Response, Defense, Metabolism, Cellular, Protein Storage and Late Embryogenesis abundant (LEA). Label free quantification (LFQ) intensities from each functional group were summed and normalized to $100 \%$. Samples were prepared in duplicate $(n=2)$.

Bottom: Proportion of protein derived from maize and F. graminearum using LFQ intensities. Functional grouping of proteins identified in the embryo. Protein IDs were manually assigned to a group depending on their organism of origin (Fusarium or maize).

Figure 3: Model of $F$. graminearum pathogenesis compared between susceptible and resistant lines of maize at different stages of infection. At early stages of contact between pathogen and host, Fusarium (orange mycelium) is able to invade the susceptible embryo cell (big black arrow) because nonspecific lipid transfer protein (nsLTP) and protease inhibitor expression is not effective (see Table 1). Inside the susceptible cell the Fusarium expresses compounds such as amylases, proteases and deoxynivalenol (DON) capable of leading to a diseased state. The resistant line may be able to prevent fungal entry and colonization (dashed arrow) because proteins such as chitinase and wound-inducible protease inhibitor 1 (WIP1) provide a more effective defense (Table 1). 


\section{References}

[1] Mohammadi M, Anoop V, Gleddie S, Harris LJ. Proteomic profiling of two maize inbreds during early gibberella ear rot infection. Proteomics 2011;11:3675-84.

[2] Goswami RS, Kistler HC. Heading for disaster: Fusarium graminearum on cereal crops. Mol Plant Pathol 2004;5:515-25.

[3] Pestka JJ, Smolinski AT. Deoxynivalenol: toxicology and potential effects on humans. J Toxicol Environ Health B Crit Rev 2005;8:39-69.

[4] Cuomo CA, Gueldener U, Xu J, Trail F, Turgeon BG, Di Pietro A, Walton JD, Ma L, Baker SE, Rep M, Adam G, Antoniw J, Baldwin T, Calvo S, Chang Y, DeCaprio D, Gale LR, Gnerre S, Goswami RS, Hammond-Kosack K, Harris LJ, Hilburn K, Kennell JC, Kroken S, Magnuson JK, Mannhaupt G, Mauceli E, Mewes H, Mitterbauer R, Muehlbauer G, Muensterkoetter M, Nelson D, O'Donnell K, Ouellet T, Qi W, Quesneville H, Roncero MIG, Seong K, Tetko IV, Urban M, Waalwijk C, Ward TJ, Yao J, Birren BW, Kistler HC. The Fusarium graminearum genome reveals a link between localized polymorphism and pathogen specialization. Science 2007;317:1400-2.

[5] Paper JM, Scott-Craig JS, Adhikari ND, Cuomo CA, Walton JD. Comparative proteomics of extracellular proteins in vitro and in planta from the pathogenic fungus Fusarium graminearum. Proteomics 2007;7:3171-83.

[6] Wanjiru W, Kang Z, Buchenauer H. Importance of cell wall degrading enzymes produced by Fusarium graminearum during infection of wheat heads. Eur J Plant Pathol 2002;108:803-10.

[7] Pekkarinen A, Mannonen L, Jones B, Niku-Paavola M. Production of proteases by Fusarium species grown on barley grains and in media containing cereal proteins. J Cereal Sci 2000;31:253-61.

[8] Jenczmionka N, Schafer W. The Gpmk1 MAP kinase of Fusarium graminearum regulates the induction of specific secreted enzymes. Curr Genet 2005;47:29-36.

[9] Kazan K, Gardiner DM, Manners JM. On the trail of a cereal killer: recent advances in Fusarium graminearum pathogenomics and host resistance. Mol Plant Pathol 2012;13:399-413.

[10] Bai G, Shaner G. Management and resistance in wheat and barley to fusarium head blight. Annu Rev Phytopathol 2004;42:135-61.

[11] Gardiner DM, Kazan K, Manners JM. Nutrient profiling reveals potent inducers of trichothecene biosynthesis in Fusarium graminearum. Fungal Genet Biol 2009;46:604-13.

[12] Audenaert K, Callewaert E, Hofte M, De Saeger S, Haesaert G. Hydrogen peroxide induced by the fungicide prothioconazole triggers deoxynivalenol (DON) production by Fusarium graminearum. BMC Microbiol 2010;10:112.

[13] Merhej J, Boutigny AL, Pinson-Gadais L, Richard-Forget F, Barreau C. Acidic pH as a determinant of TRI gene expression and trichothecene B biosynthesis in Fusarium graminearum. Food Addit Contam Part A-Chem 2010;27:710-7. 
[14] Ponts N, Pinson-Gadais L, Boutigny A, Barreau C, Richard-Forget F. Cinnamic-derived acids significantly affect Fusarium graminearum growth and in vitro synthesis of Type B trichothecenes. Phytopathology 2011;101:929-34.

[15] Mesterhazy A, Lemmens M, Reid LM. Breeding for resistance to ear rots caused by Fusarium spp. in maize - a review. Plant Breed 2012;131:1-19.

[16] Geddes J, Eudes F, Laroche A, Selinger LB. Differential expression of proteins in response to the interaction between the pathogen Fusarium graminearum and its host, Hordeum vulgare. Proteomics 2008;8:545-54.

[17] Huffaker A, Kaplan F, Vaughan MM, Dafoe NJ, Ni X, Rocca JR, Alborn HT, Teal PE, Schmelz EA. Novel acidic sesquiterpenoids constitute a dominant class of pathogen-induced phytoalexins in maize. Plant Physiol 2011;156:2082-97.

[18] Santiago R, Reid LM, Arnason JT, Zhu X, Martinez N, Malvar RA. Phenolics in maize genotypes differing in susceptibility to Gibberella stalk rot (Fusarium graminearum Schwabe). J Agric Food Chem 2007;55:5186-93.

[19] Cao A, Reid LM, Butron A, Malvar RA, Souto XC, Santiago R. Role of hydroxycinnamic acids in the infection of maize silks by Fusarium graminearum Schwabe. Mol Plant-Microbe Interact 2011;24:1020-6.

[20] van Loon LC, Rep M, Pieterse CM. Significance of inducible defense-related proteins in infected plants. Annu Rev Phytopathol 2006;44:135-62.

[21] Kang Z, Buchenauer H. Immunocytochemical localization of beta-1, 3-glucanase and chitinase in Fusarium culmorum-infected wheat spikes. Physiol Mol Plant Pathol 2002;60:141-53.

[22] Nicholson P, Gosman N, Draeger R, Thomsett M, Chandler E, Steed A. The Fusarium head blight pathosystem - status and knowledge of its components. Dordrecht, NL: Springer; 2007.

[23] Koziol AG. Application of direct-sequencing peptide proteomics to the characterization of antagonistic (endogenous and exogenous) proteins in cereal grains. PhD Thesis. University of Ottawa, Canada 2013;77-9.

[24] Reid L, Hamilton R, Schaafsma A. Automatic pipettor for inoculation of maize kernels for evaluation of resistance to Fusarium graminearum. Can J Plant Pathol -Rev Can Phytopathol 1997;19:185-7.

[25] Bradford M. Rapid and sensitive method for quantitation of microgram quantities of protein utilizing principle of protein-dye binding. Anal Biochem 1976;72:248-54.

[26] Sambrook J, Russell DW. SDS-polyacrylamide gel electrophoresis of proteins. CSH Protocols 2006;18-47.

[27] Zhou H, Ning Z, Starr AE, Abu-Farha M, Figeys D. Advancements in top-down proteomics. Anal Chem 2012;84:720-34. 
[28] Cox J, Mann M. MaxQuant enables high peptide identification rates, individualized p.p.b.-range mass accuracies and proteome-wide protein quantification. Nat Biotechnol 2008;26:1367-72.

[29] Altschul S, Gish W, Miller W, Myers E, Lipman D. Basic Local Alignment Search Tool. J Mol Biol 1990;215:403-10.

[30] Schnable PS, Ware D, Fulton RS, Stein JC, Wei F, Pasternak S, Liang C, Zhang J, Fulton L, Graves TA, Minx P, Reily AD, Courtney L, Kruchowski SS, Tomlinson C, Strong C, Delehaunty K, Fronick C, Courtney B, Rock SM, Belter E, Du F, Kim K, Abbott RM, Cotton M, Levy A, Marchetto P, Ochoa K, Jackson SM, Gillam B, Chen W, Yan L, Higginbotham J, Cardenas M, Waligorski J, Applebaum E, Phelps L, Falcone J, Kanchi K, Thane T, Scimone A, Thane N, Henke J, Wang T, Ruppert J, Shah N, Rotter K, Hodges J, Ingenthron E, Cordes M, Kohlberg S, Sgro J, Delgado B, Mead K, Chinwalla A, Leonard S, Crouse K, Collura K, Kudrna D, Currie J, He R, Angelova A, Rajasekar S, Mueller T, Lomeli R, Scara G, Ko A, Delaney K, Wissotski M, Lopez G, Campos D, Braidotti M, Ashley E, Golser W, Kim H, Lee S, Lin J, Dujmic Z, Kim W, Talag J, Zuccolo A, Fan C, Sebastian A, Kramer M, Spiegel L, Nascimento L, Zutavern T, Miller B, Ambroise C, Muller S, Spooner W, Narechania A, Ren L, Wei S, Kumari S, Faga B, Levy MJ, McMahan L, Van Buren P, Vaughn MW, Ying K, Yeh C, Emrich SJ, Jia Y, Kalyanaraman A, Hsia A, Barbazuk WB, Baucom RS, Brutnell TP, Carpita NC, Chaparro C, Chia J, Deragon J, Estill JC, Fu Y, Jeddeloh JA, Han Y, Lee H, Li P, Lisch DR, Liu S, Liu Z, Nagel DH, McCann MC, SanMiguel P, Myers AM, Nettleton D, Nguyen J, Penning BW, Ponnala L, Schneider KL, Schwartz DC, Sharma A, Soderlund C, Springer NM, Sun Q, Wang H, Waterman M, Westerman R, Wolfgruber TK, Yang L, Yu Y, Zhang L, Zhou S, Zhu Q, Bennetzen JL, Dawe RK, Jiang J, Jiang N, Presting GG, Wessler SR, Aluru S, Martienssen RA, Clifton SW, McCombie WR, Wing RA, Wilson RK. The B73 maize genome: complexity, diversity, and dynamics. Science 2009;326:1112-5.

[31] Almagro L, Ros LVG, Belchi-Navarro S, Bru R, Barcelo AR, Pedreno MA. Class III peroxidases in plant defence reactions. J Exp Bot 2009;60:377-90.

[32] Yoshimura K, Miyao K, Gaber A, Takeda T, Kanaboshi H, Miyasaka H, Shigeoka S. Enhancement of stress tolerance in transgenic tobacco plants overexpressing Chlamydomonas glutathione peroxidase in chloroplasts or cytosol. Plant J 2004;37:21-33.

[33] Sun JY, Gaudet DA, Lu ZX, Frick M, Puchalski B, Laroche A. Characterization and antifungal properties of wheat nonspecific lipid transfer proteins. Mol Plant Microbe Interact 2008;21:346-60.

[34] Gorjanovic S, Spillner E, Beljanski M, Gorjanovic R, Pavlovic M, Gojgic-Cvijanovic G. Malting barley grain non-specific lipid-transfer protein (ns-LTP): importance for grain protection. J Inst Brewing 2005;111:99-104.

[35] Molina A, Segura A, Garcia-Olmedo F. Lipid transfer proteins (nsLTPs) from barley and maize leaves are potent inhibitors of bacterial and fungal plant pathogens. FEBS Lett 1993;316:119-22.

[36] Liu D, He X, Li W, Chen C, Ge F. A beta-1, 3-glucanase gene expressed in fruit of Pyrus pyrifolia enhances resistance to several pathogenic fungi in transgenic tobacco. Eur J Plant Pathol 2013;135:26577.

[37] Mackintosh CA, Lewis J, Radmer LE, Shin S, Heinen SJ, Smith LA, Wyckoff MN, Dill-Macky R, Evans CK, Kravchenko S, Baldridge GD, Zeyen RJ, Muehlbauer GJ. Overexpression of defense response genes in transgenic wheat enhances resistance to Fusarium head blight. Plant Cell Rep 2007;26:479-88. 
[38] Emani C, Garcia J, Lopata-Finch E, Pozo M, Uribe P, Kim D, Sunilkumar G, Cook D, Kenerley C, Rathore K. Enhanced fungal resistance in transgenic cotton expressing an endochitinase gene from Trichoderma virens. Plant Biotechnol J 2003;1:321-36.

[39] Adams D. Fungal cell wall chitinases and glucanases. Microbiology (UK) 2004;150:2029-35.

[40] Cordero M, Raventos D, Sansegundo B. Expression of a maize proteinase-inhibitor gene is induced in response to wounding and fungal Infection - systemic wound-response of a monocot gene. Plant $\mathbf{J}$ 1994;6:141-50.

[41] Ryan C. Protease inhibitors in plants - genes for improving defenses against insects and pathogens. Annu Rev Phytopathol 1990;28:425-49.

[42] Roby D, Broglie K, Gaynor J, Broglie R. Regulation of a chitinase gene promoter by ethylene and elicitors in bean protoplasts. Plant Physiol 1991;97:433-9.

[43] Clarke J, Volko S, Ledford H, Ausubel F, Dong X. Roles of salicylic acid, jasmonic acid, and ethylene in cpr-induced resistance in Arabidopsis. Plant Cell 2000;12:2175-90.

[44] Szôke C, Pál M, Szalai G, Janda T, Rácz F, Marton CL. Potential role of salicylic acid in tolerance of maize to Fusarium graminearum. Acta Biol Szeged 2011;55:167-8.

[45] Ding L, Xu H, Yi H, Yang L, Kong Z, Zhang L, Xue S, Jia H, Ma Z. Resistance to hemi-biotrophic F-graminearum infection is associated with coordinated and ordered expression of diverse defense signaling pathways. PLoS One 2011;6:e19008.

[46] Yang F, Jacobsen S, Jorgensen HJ, Collinge DB, Svensson B, Finnie C. Fusarium graminearum and its interactions with cereal heads: studies in the proteomics era. Front Plant Sci 2013;4:37. 
Resistant (CO441)

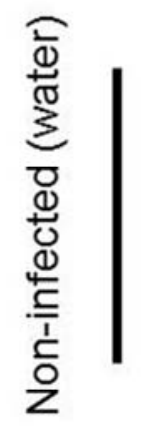

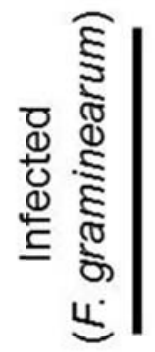
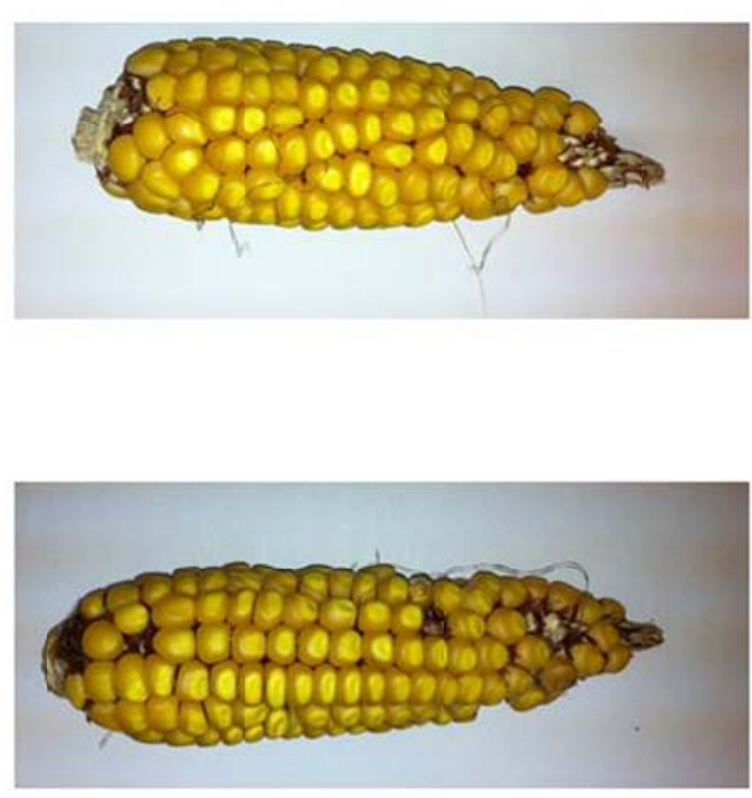

Susceptible (CL30)
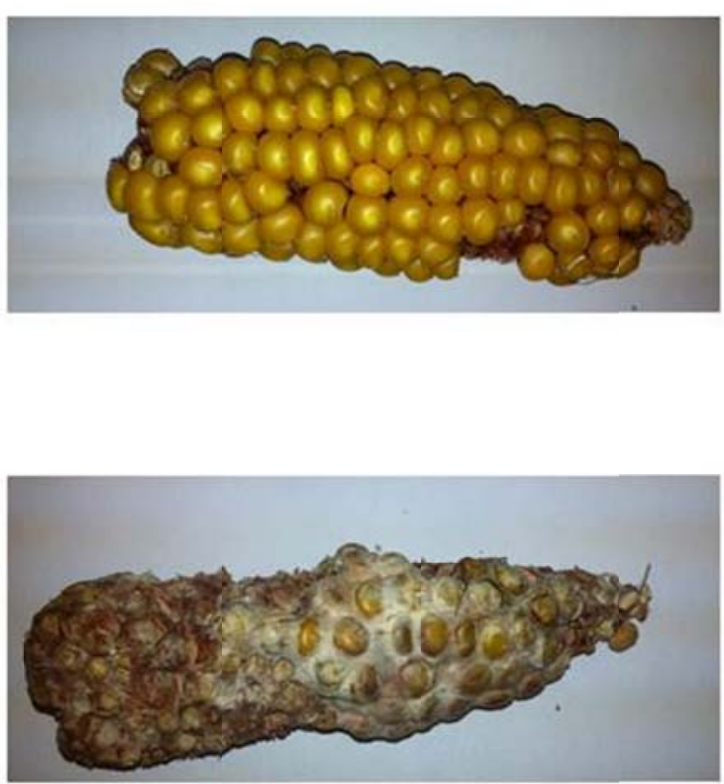

Figure 1 


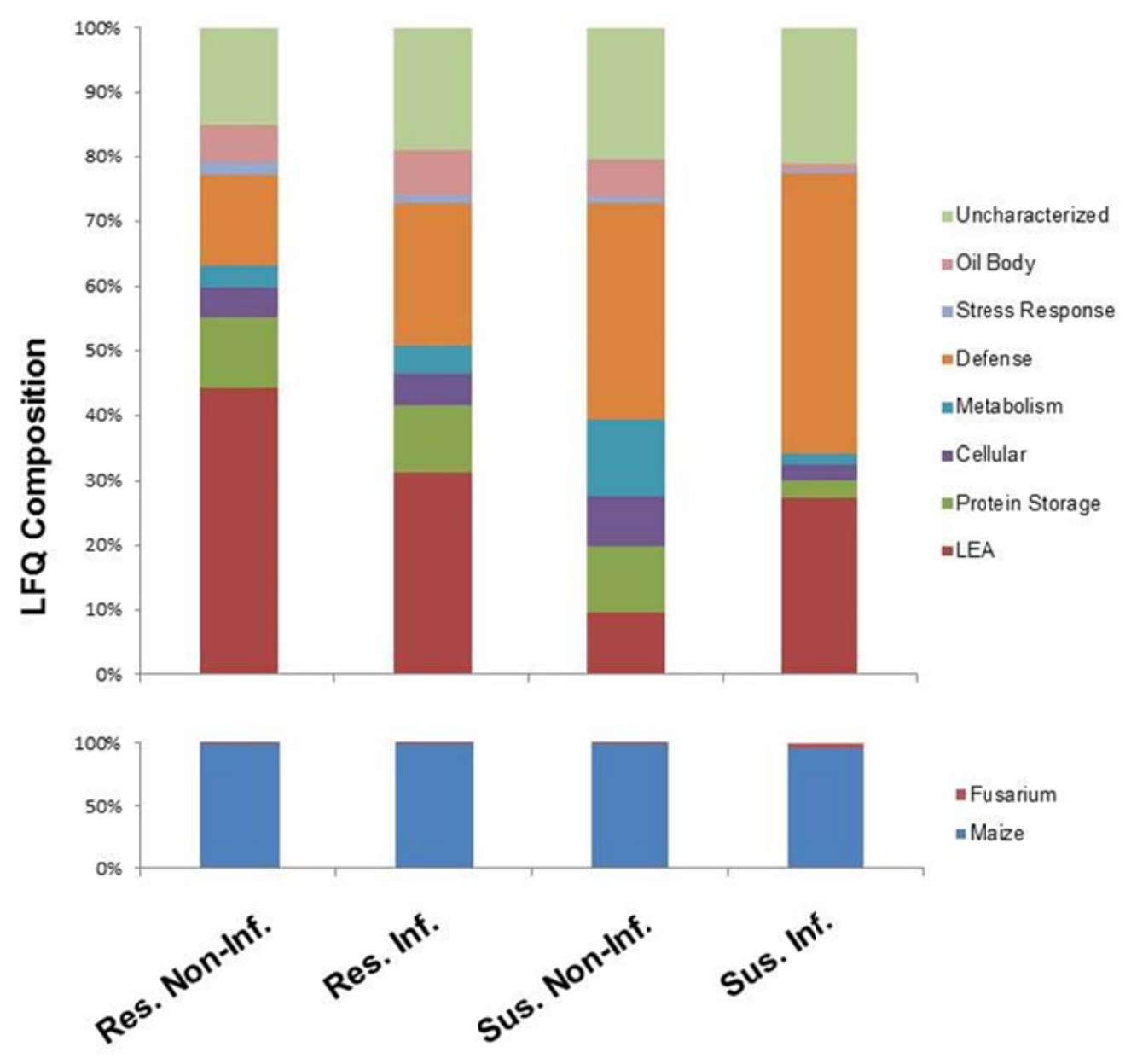

Figure 2 

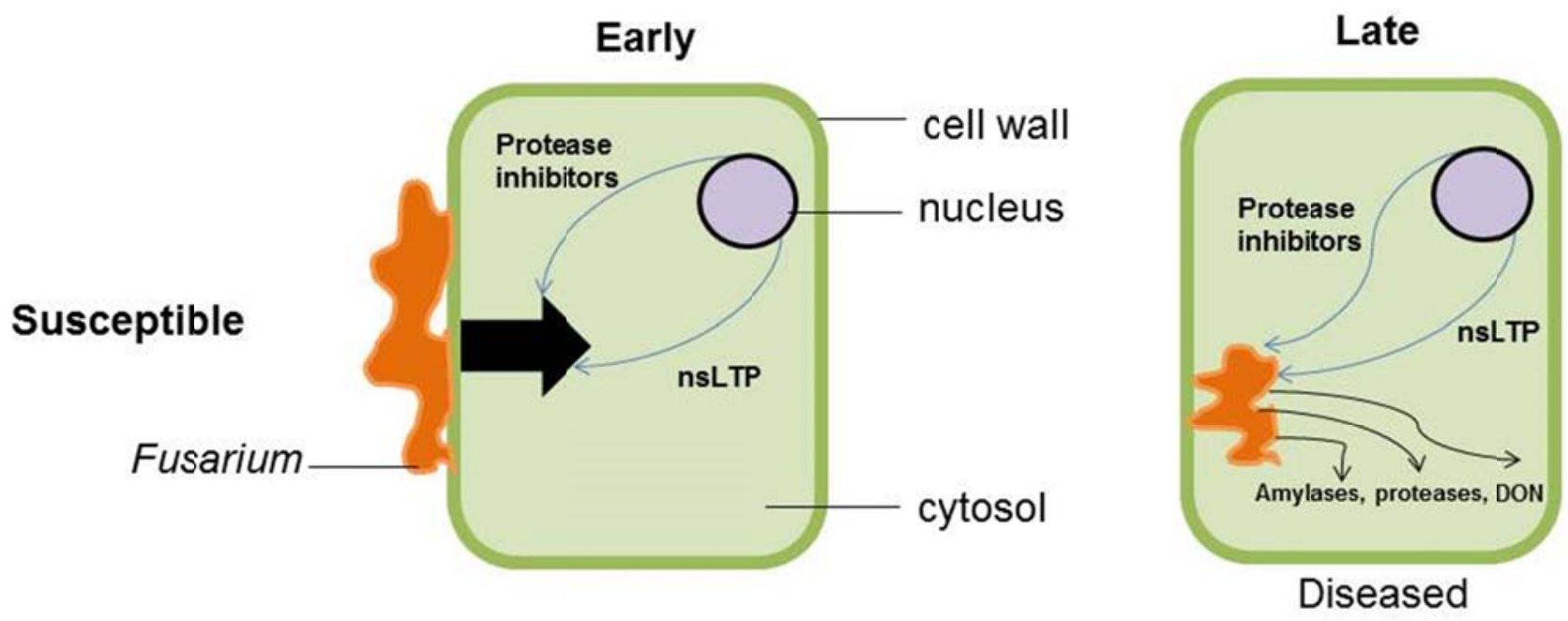

\section{Resistant}
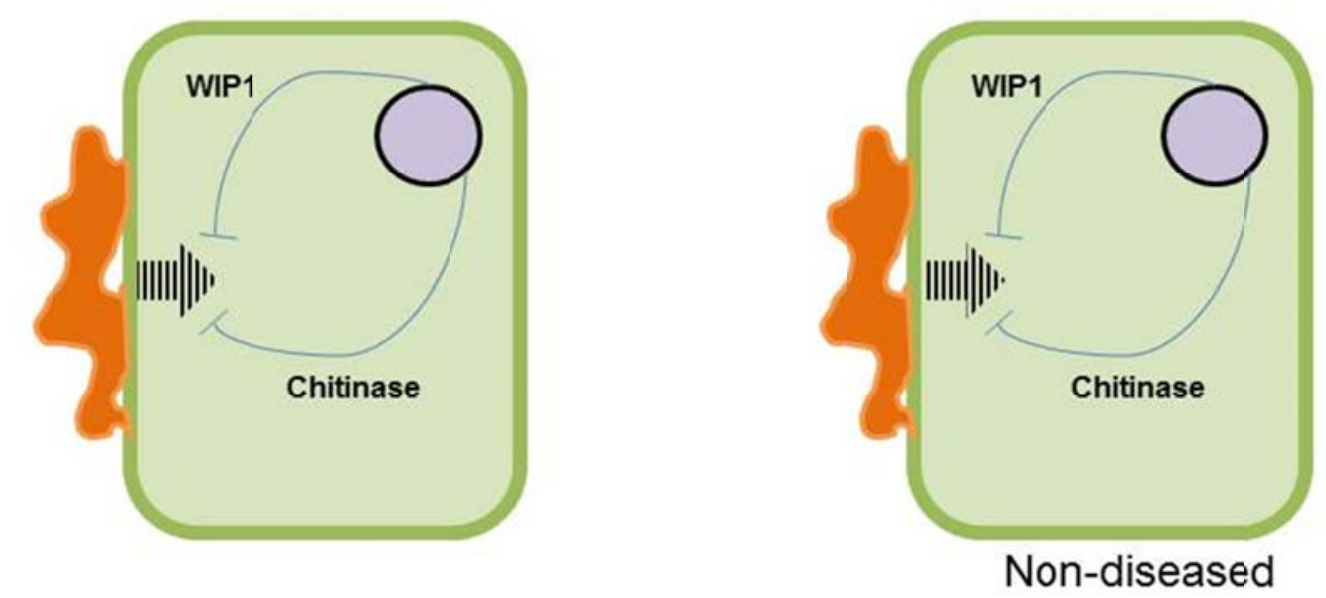

Figure 3 